\title{
Uncovering the deactivation mechanism of Au catalyst with operando high spatial resolution IR and X-ray microspectroscopy measurements
}

\author{
Elad Gross
}

Institute of Chemistry and The Center for Nanoscience and Nanotechnology, The Hebrew University of Jerusalem, Jerusalem 91904, Israel

\begin{abstract}
Detecting the reaction mechanism of multistep catalytic transformations in flow reactor is essential for optimization of these complex processes. In this study, the mechanism of catalyst deactivation within a flow reactor was studied under reaction conditions. Spectral mapping of the catalyst and the organic phase along a flow reactor, were performed with micrometer-sized synchrotron-based X-ray and IR beams, respectively, with a spatial resolution of $15 \mu \mathrm{m}$. Heterogeneous $\mathrm{Au}$ catalyst was packed in a flow reactor and activated toward the cascade reaction of pyran formation. X-ray absorption microspectroscopy measurements revealed that the highly oxidized $\mathrm{Au}(\mathrm{III})$, which is the catalytically active species, was continuously reduced along the flow reactor. IR microspectroscopy measurements detected a direct correlation between the reduction of the Au catalyst and deactivation of the catalytic process. It was observed that within $1.5 \mathrm{~mm}$ from the reactor inlet all the catalytic reactivity was quenched. Microspectroscopy measurements determined that the reduction of $\mathrm{Au}(\mathrm{III})$ was induced by nucleophilic attack of butanol, which is one of the reactants in this reaction. Slower deactivation rates were measured once the reactants concentration was decreased by an order of magnitude. Under these conditions the reaction path within the flow reactor was increased from 1.5 into $6 \mathrm{~mm}$. These results demonstrate the molecular level understanding of reaction mechanism which can be achieved by high spatial resolution microspectroscopy measurements.
\end{abstract}

\section{Introduction}

Uncovering the complex factors that direct catalytic processes is a key element for optimizing chemical reactions and designing superior catalysts, which are based on a rational design [1-4]. Various methods were developed to elucidate the complex chemistry which takes place on the surface of heterogeneous catalysts, from optical and vibrational spectroscopy (UV-Vis, Raman, IR) [5; 6] to magnetic resonance (ESR and NMR) [7] and X-ray spectroscopy (XPS) [8; 9]. 
Vibrational spectroscopy is one of the most powerful techniques for analysis of catalytic processes since it provides direct chemical information, from which the determination of the chemical structure of reactants, intermediates and products can be deduced $[6 ; 10 ; 11]$. A variety of vibrational spectroscopy methods were developed and utilized to detect the reactants into products transformation under reaction conditions. Among these methods are surface sensitive techniques such as SFG (Sum Frequency Generation) vibrational spectroscopy [12; 13] and PMIRAS (Polarization Modulation Infrared Reflection Absorption Spectroscopy) [14; 15] that can identify surface-adsorbed intermediates during catalytic reactions. In addition, high temporal resolution IR spectroscopy tools were developed and utilized to uncover the mechanism of catalytic processes [16-18].

However, all these methods do not have high spatial resolution which is required for analysis of catalytic reaction within a flow reactor. High spatial resolution IR spectroscopy can provide a detailed kinetic analysis of the progression of catalytic reactions along a flow reactor. The spatial resolution is dictated by the diffraction limit of the light and therefore the optimum resolution that can be gained in IR measurements is in the order of $\sim 10 \mu \mathrm{m}$. The spatial resolution is mainly controlled by the spot size of the beam, which in most of the FTIR setups is wider than $0.1 \mathrm{~cm}$. As a consequence, the spatial resolution of these techniques is lower by three orders of magnitude than the light diffraction limit and they provide only averaged chemical information from the entire probed area $[19 ; 20]$.

High spatial resolution IR mapping can be achieved by using synchrotron IR light as a source for vibrational spectroscopy measurements $[1 ; 10 ; 21 ; 22]$. The high photon flux of this source makes it possible to reduce the aperture down to a few micrometers with negligible decrease in the sensitivity, providing an IR beam spot size of $\sim 10 \mu \mathrm{m}$. Several initial studies have demonstrated that synchrotron IR microspectroscopy measurements can track the progression of catalytic reactions in which zeolites and supported nanoparticles are used as catalysts [21; 23-25].

For example, it was recently demonstrated that the catalytic reactivity within ZSM-5 crystals can be detected with IR microspectroscopy measurements [25]. The chemical structures of intermediates, which are formed during styrene oligomerization reaction, were monitored with synchrotron-based IR micro-spectroscopy.

We have recently demonstrated that a detailed kinetic analysis of a multistep organic transformation can be achieved with synchrotron-based IR microspectroscopy measurements [21]. Heterogeneous Au catalyst was packed in a flow reactor and activated the cascade reaction 
of dihydropyran formation. High spatial resolution mapping of the reactants, intermediates and products along the flow reactor was performed with synchrotron-sourced IR beam. Full kinetic analysis of the catalytic reaction was accomplished by analyzing the IR microspectroscopy spectra at different points along the flow reactor.

In this study, we further analyzed the Au-catalyzed dihydropyran formation reaction, determining the deactivation mechanism of the catalyst under flow conditions. The chemical and electronic properties of the organic phase and the Au catalyst along the flow reactor were determined under reaction conditions with $\mu \mathrm{m}$-sized, synchrotron-sourced, IR and X-ray beams (Fig.1). These measurements clarified the reasons for deactivation of the $\mathrm{Au}$ catalyst. NEXAFS microspectroscopy measurements revealed that under flow reaction conditions the Au catalyst is reduced from the catalytically-active species, $\mathrm{Au}(\mathrm{III})$, into non-active species. Accordingly, IR microspectroscopy measurements detected that the reduction of the Au catalyst was followed by quenching of the catalytic reactivity. Kinetic measurements revealed that the presence of butanol, which is one of the reactants in this reaction, can either directly or indirectly reduce the catalytically-active $\mathrm{Au}(\mathrm{III})$ species into its catalytically-inert metallic state. Different approaches to minimize and delay the deactivation process are discussed in the paper.

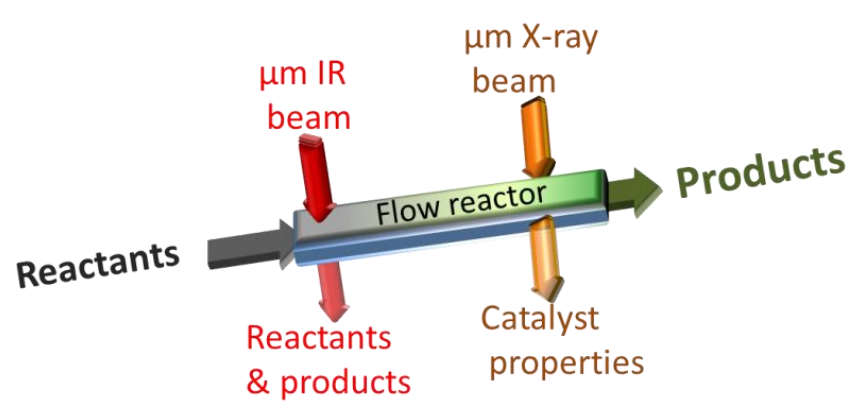

Fig. 1: Schematic representation of the experimental setup. Flow micro-reactor was packed with heterogeneous $\mathrm{Au}$ catalyst. Micrometer-sized IR and X-ray beams from a synchrotron detected the vibrational spectra of organic molecules and the oxidation state of the catalyst, respectively. These measurements were conducted along the flow reactor with a spatial resolution of $10 \mu \mathrm{m}$.

\section{Experimental setup}

$\mathrm{Au}$ nanoparticles with a diameter of $2.0 \pm 0.3 \mathrm{~nm}$ were prepared by encapsulating $\mathrm{Au}$ ions in a G4-PAMAM (Polyamidoamine) dendrimer matrix. Following their encapsulation, the Au ions were reduced into $\mathrm{Au}$ nanoparticles by the addition of $\mathrm{NaBH}_{4}$ into the reaction mixture (Fig. 2a) [26; 27]. The encapsulated nanoparticles were loaded on mesoporous silica support (SBA-15) with a surface area of $760 \mathrm{~m}^{2} \mathrm{~g}^{-1}$. The pore diameter of the mesoporous silica was $7 \pm 1 \mathrm{~nm}$ and therefore the dendrimer-encapsulated Au nanoparticles were easily deposited in the pores of the mesoporous support with high distribution and without aggregation. The dendrimer-encapsulated 
$\mathrm{Au}$ nanoparticles were anchored onto the walls of the mesoporous support by hydrogen bonds which were formed between the OH-terminated G4-PAMAM dendrimer (G4-OH) and the $\mathrm{SiO}_{2}$ surface [28]. This interaction prevented the detachment of dendrimer-encapsulated $\mathrm{Au}$ nanoparticles from the mesoporous $\mathrm{SiO}_{2}$ support, even under liquid phase reaction conditions [29].

a.

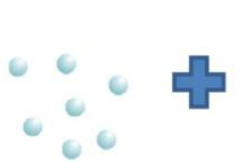

$\mathrm{HAuCl}_{4}$

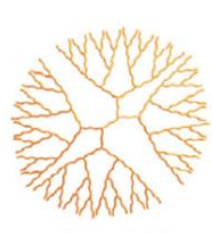

$\mathrm{G} 4-\mathrm{OH}$ dendrimer

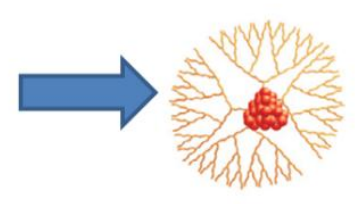

Au@G4-OH

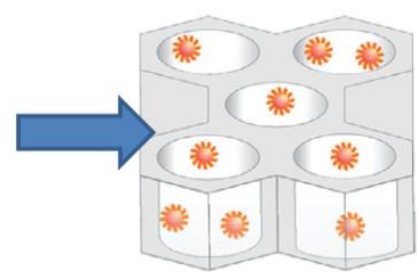

Au@G4-OH/SBA-15

b.

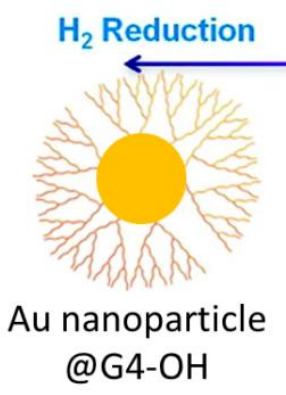

$\mathrm{PhICl}_{2}$ Oxidation
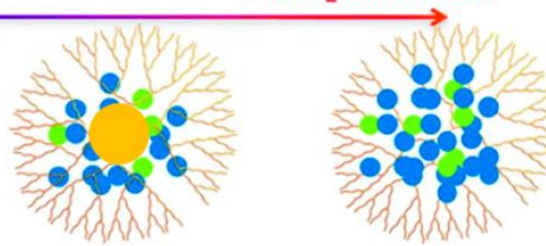

$\mathrm{Au}(\mathrm{III})$ ions

@G4-OH

Fig. 2: a. Preparation scheme of dendrimer-encapsulated Au nanoparticles and their deposition within the pores of mesoporous silica (SBA-15). b. The dendrimer-encapsulated Au nanoparticles (marked in yellow circle) can be oxidized into the catalytically active $\mathrm{Au}(\mathrm{III})$ ions (green circles) along with formation of chloride ions (blue circles) by the addition of an inorganic oxidizer, $\mathrm{PhICl}_{2}$, into the solution. The Au ions can be reduced back to their metallic state by exposure to $\mathrm{H}_{2}$. The oxidationreduction process is reversible. No leaching of $\mathrm{Au}$ ions to the solution phase was detected throughout the oxidation and reduction cycles.

The small size of the encapsulated metallic nanoparticles enabled their oxidation from $\mathrm{Au}(0)$ into $\mathrm{Au}$ (III) by the addition of an inorganic oxidizer, $\mathrm{PhICl}_{2}$, into the solution phase (Fig. 2b). No leaching of Au ions was detected following the oxidation of the Au nanoparticles into Au ions. The high stability of the Au ions is due to their encapsulation within the dendrimer matrix [30; 31]. The oxidation process is reversible and the $\mathrm{Au}$ ions can be reduced back to $\mathrm{Au}(0)$ following an exposure to $\mathrm{H}_{2}$. It was previously demonstrated that the oxidation of $\mathrm{Au}$ into $\mathrm{Au}(\mathrm{III})$ activates the $\mathrm{Au}$ catalyst toward a variety of $\pi$-bond activation reactions which are mainly activated by homogenous Au catalysts [30-32].

The Au@G4-OH/SBA-15 catalyst was deposited in a designated IR flow cell. The cell was constructed of two $\mathrm{CaF}_{2}$ windows, which were separated by a $0.2 \mathrm{~mm}$ thick Teflon sheet. Prior to 
the X-ray microspectroscopy measurements the catalyst was packed inside a quartz rod (ID 250 $\mu \mathrm{m})$. Each reactor was connected to a syringe pump for continuous delivery of solvents into the flow reactor. These two reactors that were specifically-designed for in-situ synchrotron-sourced IR and the X-ray measurements have similar inner volume and diameter, ensuring comparable residence time of the reactants. No leaching of metal ions to the solution phase was detected during the catalytic flow reaction. The outlet of the cells was connected to a GC for continuous analysis of products formation. The supernatant was collected and analyzed by GC and NMR. GC analysis verified that the catalytic yield and products selectivity in the IR and X-ray reactors were comparable (with variations of up to $\pm 15 \%$ ).

Prior to the catalytic reaction, the dendrimer encapsulated Au nanoparticles were oxidized from $\mathrm{Au}(0)$ into $\mathrm{Au}(\mathrm{III})$ by exposure of the catalyst to a solution of toluene in which $0.02 \mathrm{M}$ of $\mathrm{PHICl}_{2}$ was dissolved. The catalytic reaction was performed by flowing $0.5 \mathrm{mmol}$ of vinylether $\mathbf{1}, 0.5$ mmol of butanol- $\mathrm{d}_{10}$ and $0.05 \mathrm{mmol}$ of $\mathrm{PhICl}_{2}$, which were solvated in $10 \mathrm{ml}$ toluene- $\mathrm{d}_{8}$, through the pre-oxidized $\mathrm{Au}$ catalyst at room temperature. The oxidation of the catalyst prior to the flow reaction and the addition of a catalytic amount of $\mathrm{PhICl}_{2}$ to the reactants solution were both proved to be essential for activation of the Au catalyst. Without the addition of $\mathrm{PhICl}_{2}$ into the reactant solution the pre-oxidized, catalytically-active, $\mathrm{Au}(\mathrm{III})$ specie was quickly reduced into the catalytically-inert $\mathrm{Au}(0)$ species.

The oxidation state of the catalyst along the flow reactor was studied under reaction conditions with NEXAFS microspectroscopy. X-ray absorption spectroscopy measurements were conducted at beam line 10.3.2 of the ALS (Advanced Light Source) at LBNL (Lawrence Berkeley National Laboratory). The data was collected in fluorescence mode at the Au L3 edge (11.918 KeV) with a spot size of 16X6 $\mu \mathrm{m}$. IR absorption spectroscopy measurements were conducted at beam line 1.4.4 of the Advanced Light Source (ALS) at Lawrence Berkeley National Laboratory (LBNL) employing a Thermo Nicolet Nexus 870 and Continu $\mu$ m XL IR microscope. Line scanning of up to $15 \mathrm{~mm}$ was performed along the flow reactor with $15 \mu \mathrm{m}$ steps, $4 \mathrm{~cm}^{-1}$ spectral resolution and averaging of 256 scans.

\section{Results and discussion}

Cascade dihydropyran synthesis was chosen as a test reaction for 1D microspectroscopy IR mapping of multistep organic reaction within a flow micro-reactor (Fig. 3). In this reaction, propargyl vinyl ether $\mathbf{1}$ is catalytically rearranged by the Au catalyst to the primary product allenic aldehyde $\mathbf{2}$. Activation of the primary product $\mathbf{2}$ by the Au catalyst is followed by 
nucleophilic attack of butanol which induces the formation of the secondary product, acetal 3. In the first part of the reaction, which is a unimolecular process, the Au catalyst activates the transformation of reactant $\mathbf{1}$ into product 2 . In the second part of the reaction, which is a bimolecular process, the Au catalyst activates the reactant 2. Following its activation, allenic aldehyde 2 interacts with butanol for the formation of the final product 3. It was previously shown that cascade dihydropyran reaction can be catalyzed by homogeneous Au complexes [33]. In a recent paper we demonstrated that following oxidation of the Au nanoparticles with $\mathrm{PhICl}_{2}$ into the catalytically active $\mathrm{Au}(\mathrm{III})$ species, the dendrimer-encapsulated $\mathrm{Au}$ nanoparticles can activate the dihydropyran formation reaction [31]. Though alcohol is necessary only in the second step of the reaction (transformation of product $\mathbf{2}$ into $\mathbf{3}$ ), in the continuous flow setup the alcohol was added to the reactants solution and was present throughout the catalytic process. As will be discussed in the next paragraphs, the addition of alcohol to the reaction mixture initiated undesired side-reactions that induced the deactivation of the catalyst.

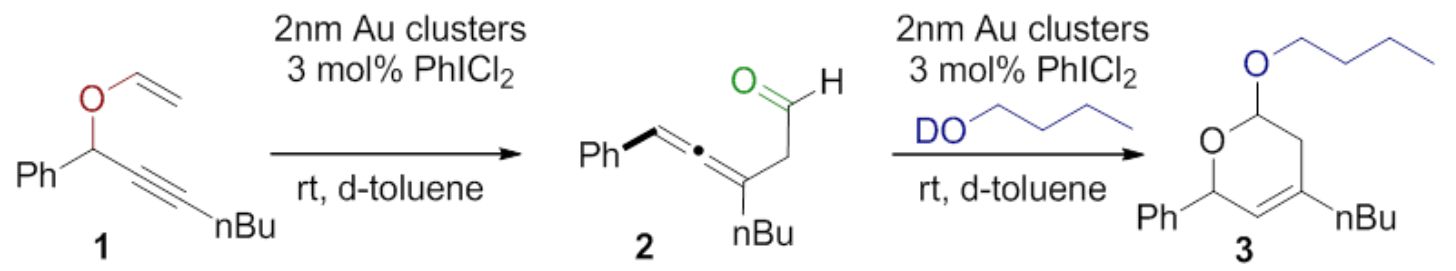

Fig. 3: Cascade dihydropyran synthesis was chosen as a test reaction for 1D microspectroscopy IR mapping of organic transformation in flow reactor. In this reaction, which is catalyzed by heterogeneous Au catalysts, propargyl vinyl ether $\mathbf{1}$ is catalytically rearranged to the primary product allenic aldehyde $\mathbf{2}$. Activation of the primary product $\mathbf{2}$ by the Au catalyst is followed by nucleophilic attack of butanol- $\mathrm{d}_{10}$ which induced the formation of the secondary product, acetal 3. In the flow reaction, both vinylether 1 and butanol- $\mathrm{d}_{10}$ were added into the reaction mixture. It should be noted however that butanol- $\mathrm{d}_{10}$ is only consumed in the second step of the catalytic reaction in which allenic aldehyde $\mathbf{2}$ is transformed into acetal $\mathbf{3}$.

The catalytic reactivity and products selectivity were analyzed by GC and NMR measurements of the supernatant. High yield (75\%) and high products selectivity, with 2:3 ratio of 0:100, were detected with a reactants flow rate of $0.2 \mathrm{ml} / \mathrm{hr}$. These results indicate that under these reaction conditions the primary product was completely transformed into the final product and therefore could not be detected in the supernatant.

The oxidation state of the catalyst along the flow reactor was studied under reaction conditions with NEXAFS microspectroscopy. NEXAFS measurements were conducted along the flow reactor under steady-state reaction conditions (Fig. 4a). The measurements were conducted at distances (Z) of 0, 2 and $4 \mathrm{~mm}$ from the inlet (Fig. 4b). Reference NEXAFS spectra of $\mathrm{Au}(0)(\mathrm{Au}$ foil), $\mathrm{Au}(\mathrm{I})\left(\left(\mathrm{Ph}_{3} \mathrm{P}\right) \mathrm{AuCl}\right)$ and $\mathrm{Au}(\mathrm{III})\left(\mathrm{AuCl}_{3}\right)$ are shown in Fig. $4 \mathrm{c}$. For analysis of the oxidation 
state of the Au nanoparticles at different points along the flow reactor, the measured near-edge spectra was fit by a linear combination to the reference spectra of $\mathrm{Au}(0), \mathrm{Au}(\mathrm{I})$ and $\mathrm{Au}(\mathrm{III})$.

At $Z=0$, which is the entrance point of reactants into the flow reactor (red curve in Fig. $4 \mathrm{~b}$ ), most of the Au catalyst was oxidized into Au(III). NEXAFS measurements that were conducted at higher $\mathrm{Z}$ values indicated that the Au catalyst is being continuously reduced along the flow reactor. The ratio of the $\mathrm{Au}(\mathrm{III})$ within the NEXAFS signal decreased from $95 \%$ to $75 \%$ and then to $65 \%$ as the $Z$ value increased from 0 to 2 and $4 \mathrm{~mm}$, respectively (green and blue curves in Fig. 4b). Interestingly, under these reaction conditions the catalytically active $\mathrm{Au}(\mathrm{III})$ was mainly reduced into $\mathrm{Au}(\mathrm{I})$, with almost no $\mathrm{Au}(0)$ signal.
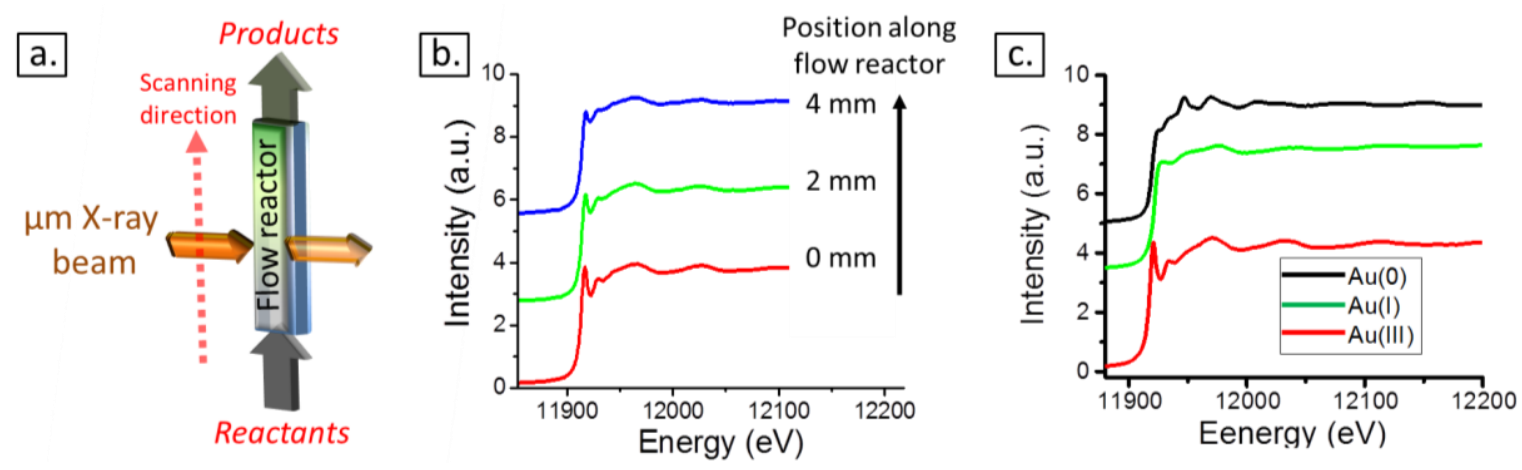

Fig. 4: a. Schematic representation of the experimental setup in which X-ray absorption measurements were conducted along the flow reactor under reaction conditions. b. NEXAFS measurements were performed at different points along the flow reactor. Prior to the reaction the Au nanoparticles were oxidized by the addition of $10 \mathrm{~mol} \% \mathrm{PhICl}_{2}$ to the solution phase. The Au(III) signal in the NEXAFS measurement decreased at longer distances from the inlet. c. Reference NEXAFS spectra of $\mathrm{Au}(0)(\mathrm{Au}$ foil $), \mathrm{Au}(\mathrm{I})\left(\left(\mathrm{Ph}_{3} \mathrm{P}\right) \mathrm{AuCl}\right)$ and $\mathrm{Au}(\mathrm{III})\left(\mathrm{AuCl}_{3}\right)$.

IR microspectroscopy measurements were performed under flow conditions with reactants concentration of $0.1 \mathrm{M}$ and flow rate of $5 \mathrm{ml} / \mathrm{hr}$. As obtained in Fig. 5a, no changes in the features of the IR spectra were detected beyond $1.5 \mathrm{~mm}$ from the inlet of the flow reactor. Though large quantities of reactants are still present throughout the flow reactor, as detected by the strong IR absorption peak at $1250-1350 \mathrm{~cm}^{-1}$ which is correlated to the reactant's C-O-C vibration, after 1.5 $\mathrm{mm}$ there were no detectable reactants transformation into products. In addition, no changes could be detected in the weak IR absorption feature at $1750 \mathrm{~cm}^{-1}$, which is correlated to the $\mathrm{C}=\mathrm{O}$ vibration of the primary product. These two observations indicate that even though both the reactant and the primary product were detected in the flow reactor, no transformation from reactant into primary product or from primary into secondary product could be identified at distances which are longer than $1.5 \mathrm{~mm}$ from the inlet. These results directly link between the 
decrease in the concentration of $\mathrm{Au}(\mathrm{III})$, as detected by $\mathrm{X}$-ray microspectroscopy, and the deactivation of the catalytic process.
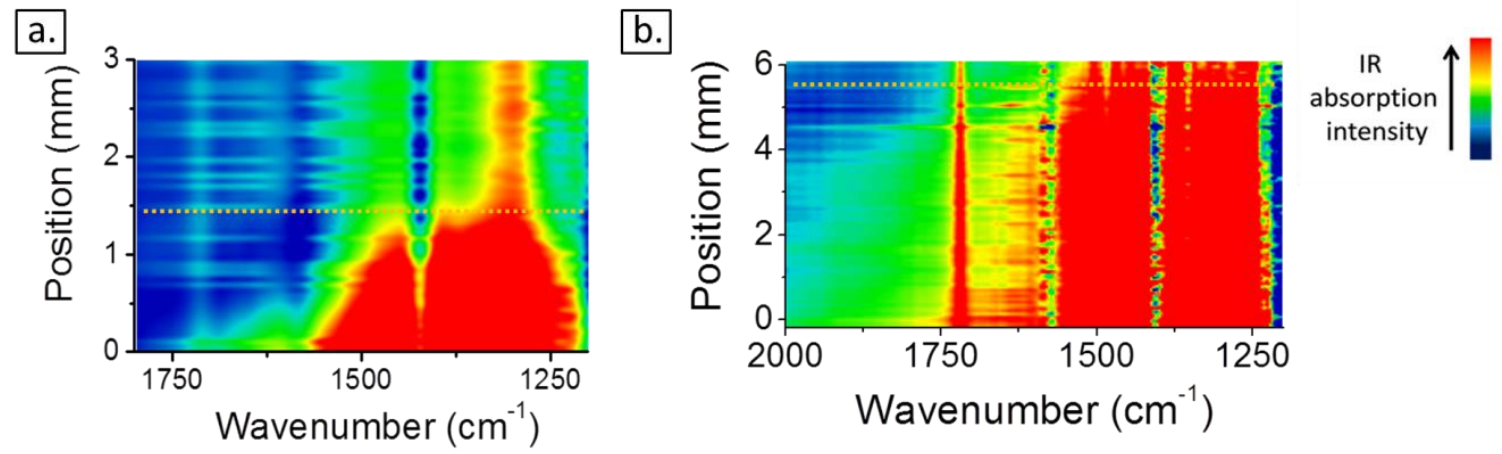

Fig. 5: a. IR microspectroscopy mapping along the flow reactor at flow rate of $5 \mathrm{ml} / \mathrm{hr}$ with reactants (propargyl vinyl ether 1 and butanol- $\mathrm{d}_{10}$ ) concentration of $0.1 \mathrm{M}$ and $0.01 \mathrm{M}$ of $\mathrm{PhICl}_{2}$. It can be observed no changes in the IR spectra can be detected beyond $1.5 \mathrm{~mm}$ in the flow reactor (marked with a dashed yellow line), which indicates that the catalytic reactivity has stopped at this point. b. IR microspectroscopy mapping along the flow reactor at flow rate of $5 \mathrm{ml} / \mathrm{hr}$ with reactants (both propargyl vinyl ether 1 and butanol- $\mathrm{d}_{10}$ ) concentration of $0.01 \mathrm{M}$. The concentration of $\mathrm{PhICl}_{2}$ in the reaction mixture was $0.01 \mathrm{M}$ as well. The gradual changes in the FTIR features indicate that the catalytic reaction proceeds up to a distance of $6 \mathrm{~mm}$ from the inlet.

Our hypothesis is that the source for the deactivation is the presence of butanol within the flow reactor [34]. The nucleophilic properties of butanol, which is one of the reactants in the cascade dihydropyran formation reaction, can induce either directly or indirectly the reduction of the catalytically-active $\mathrm{Au}(\mathrm{III})$ species. In direct oxidation-reduction process the reduction of $\mathrm{Au}(\mathrm{III})$ will be followed by oxidation of butanol into butyraldehyde. An indirect reduction route can occur if the butanol attacks the oxidizer, $\mathrm{PhICl}_{2}$ and decrease its concentration along the flow reactor. Lower concentration of oxidizer in the flow reactor will lead to reduction of the $\mathrm{Au}(\mathrm{III})$ species. The consequences in both scenarios are similar, the catalytically active species, Au(III), would be reduced and butanol would be oxidized into butyraldehyde.

In order to test this hypothesis we conducted another experiment in which $0.25 \mathrm{M}$ butanol- $\mathrm{d}_{10}$ and $5 \mathrm{mM} \mathrm{PhICl}{ }_{2}$ were injected into the catalyst-packed flow reactor at of flow rate of $5 \mathrm{ml} / \mathrm{hr}$. IR microspectroscopy measurements were conducted along the flow reactor to detect the formation of butyraldehyde, which will indicate that butnol is being oxidized within the flow reactor. Gradual formation of butyraldehyde was detected by the appearance of an IR absorption peak at $1700 \mathrm{~cm}^{-1}$ within $2 \mathrm{~mm}$ from the inlet of the flow reactor (Fig. 6). It should be emphasized that in this experiment no reactant was introduced into the flow cell and therefore the aldehyde formation can be solely correlated to butanol oxidation. These results verify our hypothesis that under reaction conditions butanol is being oxidized. The oxidation of butanol will decrease the 
concentration of $\mathrm{PHICl}_{2}$ in the reaction mixture, which will lead to the reduction and deactivation of the Au catalyst.

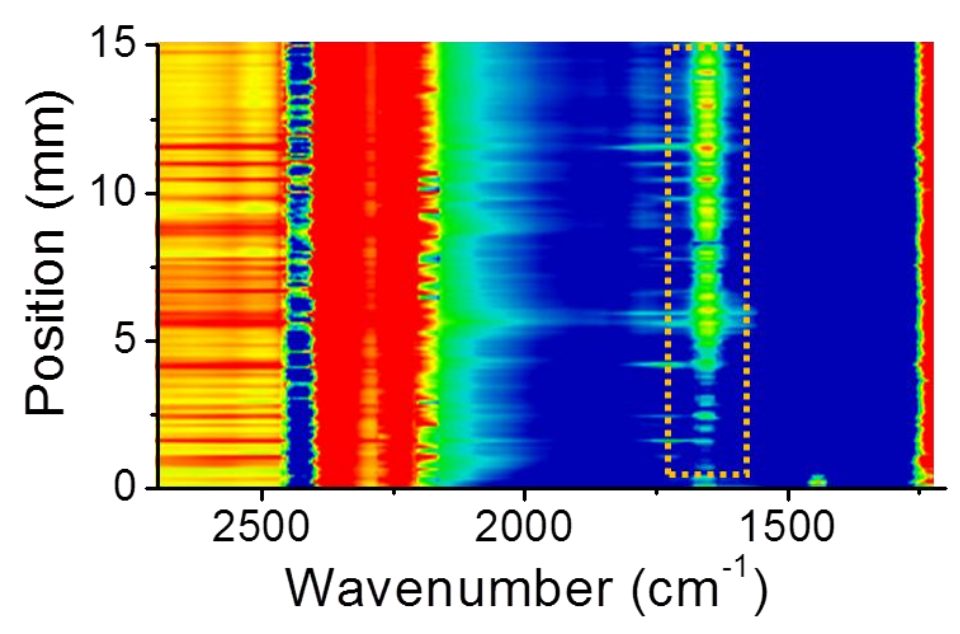

Fig. 6: IR microspectroscopy mapping along the flow reactor in which $0.25 \mathrm{M}$ butanol-d $\mathrm{d}_{10}$ and $5 \mathrm{mM} \quad \mathrm{PhICl}_{2}$ were flowed through the catalyst-packed reactor at flow rate of $5 \mathrm{ml} / \mathrm{hr}$. The formation of an aldehyde is detected by the appearance of a $\mathrm{C}=\mathrm{O}$ absorption feature at $1700 \mathrm{~cm}^{-1}$.

These results explain the essential role of $\mathrm{PhICl}_{2}$ in the reaction mixture, even though the $\mathrm{Au}$ catalyst was oxidized prior to the catalytic process. Only by the presence of $\mathrm{PhICl}_{2}$ in the reaction mixture the concentration of $\mathrm{Au}(\mathrm{III})$ can be kept constant in the presence of a reducing alcohol in the solution mixture. However, the reduction-oxidation equilibrium is slowly distorted since the $\mathrm{PHICl}_{2}$, which is present in a relatively low concentration $(0.05 \mathrm{mmol})$ in the reaction solution, is being slowly consumed throughout this process. The consumption of $\mathrm{PhICl}_{2}$ is either by its direct interaction with the alcohol or by its interaction with the reduced Au catalyst. The amount of butanol $(0.5 \mathrm{mmol})$ is higher by an order of magnitude than that of $\mathrm{PhICl}_{2}$. As the concentration of $\mathrm{PhICl}_{2}$ in the flow reactor decreases, the impact of butanol will be more dominant and will lead to eventual deactivation of the catalyst by reduction of the $\mathrm{Au}(\mathrm{III})$ species.

Since butanol was found as the cause for deactivation of the catalyst, it was hypothesized that by decreasing the inlet concentration of the two reactants, propargyl vinyl ether $\mathbf{1}$ and butanol, the deactivation process could be delayed. IR microspectroscopy mapping of the flow reactor was conducted with reactants (propargyl vinyl ether $\mathbf{1}$ and butanol- $\mathrm{d}_{10}$ ) concentration of $0.01 \mathrm{M}$ and flow rate of $5 \mathrm{ml} / \mathrm{hr}$ (Fig. 5b). It should be noted that the concentration of $\mathrm{PhICl}_{2}$ was not changed in this experiment and was $0.01 \mathrm{M}$. Under these reaction conditions, in which the concentration of reactants (propargyl vinyl ether $\mathbf{1}$ and butanol- $\mathrm{d}_{10}$ ) is equal to the concentration of $\mathrm{PhICl}_{2}$, gradual changes in the IR spectra were detected up to $6 \mathrm{~mm}$ within the flow reactor. A continuous decrease in the IR absorption at $1750 \mathrm{~cm}^{-1}$, which is correlated to the primary product, allenic aldehyde $\mathbf{2}$, indicates that the aldehyde is being consumed and catalytically transformed into the secondary product, acetal 3. Gradual decrease was also obtained in the reactant IR peak (1100- 
$1650 \mathrm{~cm}^{-1}$ ). These changes indicate that the reactants are being continuously consumed in the catalytic process. Primary and secondary products formation, under these reaction conditions, was detected by NMR and GC analysis of the supernatant.

IR microspectroscopy mapping reveals that under these reaction conditions a continuous catalytic transformation occurs up to $6 \mathrm{~mm}$ within the flow reactor. By decreasing the inlet concentration of the reactants by an order of magnitude the deactivation process was delayed and the catalytically active area in the flow reactor was increased by more than 4 fold.

Kinetic analysis of the cascade reaction with reactants concentration of $0.1 \mathrm{M}$ and $0.01 \mathrm{M}$ was performed by integrating the IR absorption peaks of the reactants and products as function of the measurement position in the flow reactor (Fig. 7a and b, respectively). The IR absorption peaks were converted to concentration values (mol/L) according to GC analysis of the supernatant after the catalytic reaction.
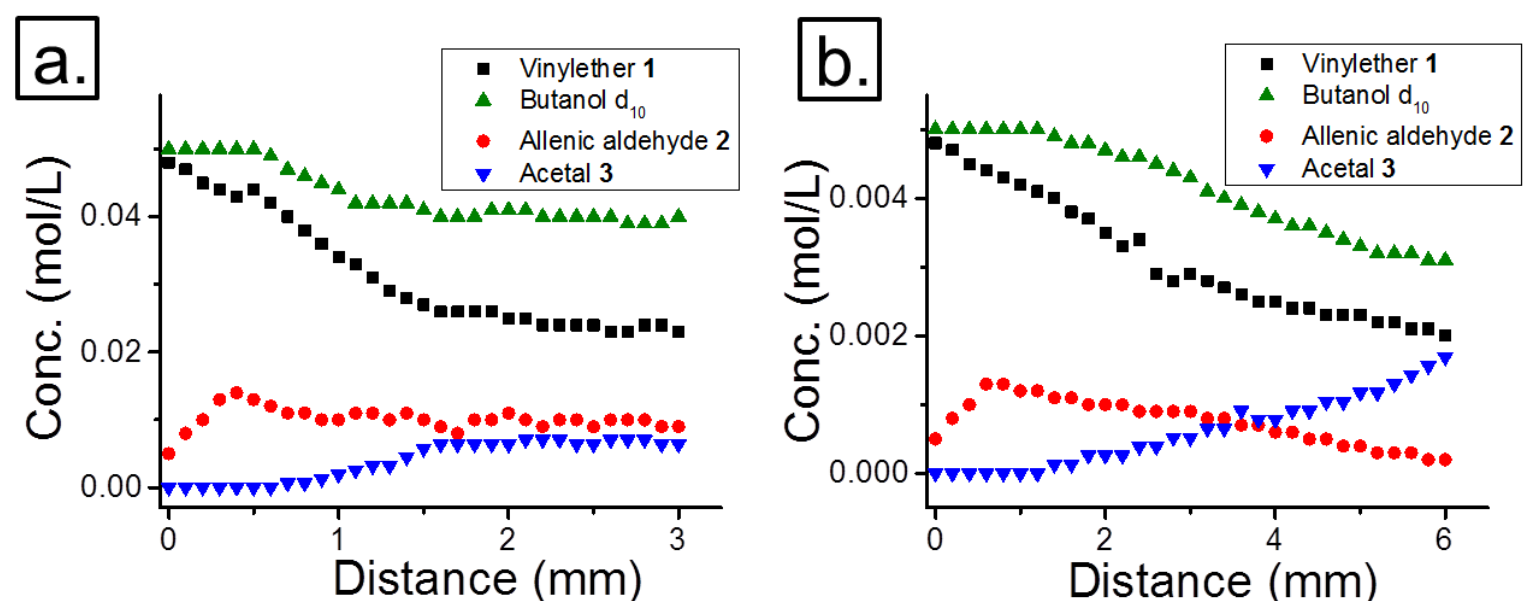

Fig. 7: Analysis of reactants and products distribution as function of time on stream and location along the flow reactor at flow rate of $5 \mathrm{ml} / \mathrm{hr}$ and with reactants concentration of $0.1 \mathrm{M}(\mathbf{a}$.$) and 0.01 \mathrm{M}(\mathbf{b}$.). The reactants and products absorption values were integrated from the matching IR absorption peak areas and converted to concentration based on GC analysis of the solution.

The kinetic analysis of the reaction with reactants concentration of $0.1 \mathrm{M}$ indicates as well that the reaction was quenched after $1.5 \mathrm{~mm}$ (Fig. 7a). At this stage of the reaction the products ratio of Allenic aldehyde $\mathbf{2}$ and Acetal $\mathbf{3}$ was almost 1:1 with a total products yield of $40 \%$. When the concentration of the reactants was decreased by an order of magnitude to $0.01 \mathrm{M}$ a progression in the catalytic reaction was detected up to $6 \mathrm{~mm}$ within the flow reactor (Fig. 7b). In this case, the products ratio of Allenic aldehyde $\mathbf{2}$ and Acetal $\mathbf{3}$ was close to 1:4 with a total products yield of $60 \%$. The simultaneous decrease in the concentration of Allenic aldehyde 2 and butanol- $\mathrm{d}_{10}$ 
indicates that the transformation of Allenic aldehyde $\mathbf{2}$ into Acetal 3, in which butanol- $\mathrm{d}_{10}$ is consumed, is faster than the formation of Allenic aldehyde 2. In both reactants concentration of $0.1 \mathrm{M}$ and $0.01 \mathrm{M}$, it was observed that during the initial phase of the reaction $(0-1 \mathrm{~mm})$ the concentration of reactant $\mathbf{1}$ was gradually decreasing due to formation of primary product $\mathbf{2}$. During this incubation time, no formation of the secondary product 3 was detected [21].

\section{Conclusions}

We have utilized $\mu \mathrm{m}$-sized synchrotron-sourced IR and X-ray beams for 1D mapping of the organic phase and the metallic catalyst during the multistep reaction of dihydropyran formation. The measurements were performed along a flow reactor with spatial resolution of $15 \mu \mathrm{m}$. Direct correlation was obtained between the reduction of the catalyst from $\mathrm{Au}(\mathrm{III})$ into $\mathrm{Au}(\mathrm{I})$, as detected by X-ray microspectroscopy and quenching of the catalytic reaction, as detected by IR microspectroscopy. IR microspectroscopy mapping resolved that the reason for deactivation of the Au catalyst is either its direct or indirect reduction by butanol, which is one of the reactants. We demonstrated that by tuning the concentration of the reactants, the deactivation rate could be significantly decreased.

As demonstrated in this work, the mechanism of catalytic reactions and the reasons for deactivation can be determined with high spatial resolution mapping of the catalytic process within a flow reactor. Operando spectroscopy measurements of organic transformations in flow reactor with high spatial resolution are potentially applicable to numerous catalytic and stoichiometric organic reactions $[35 ; 36]$. The spectroscopic tools that were introduced in this paper can be further utilized to probe and improve the catalytic yield and selectivity of a variety of organic transformations that are conducted in flow reactors [37].

\section{Acknowledgments}

Synchrotron measurements were performed at the Advanced Light Source (ALS) at Lawrence Berkeley National Laboratory (LBNL). The Advanced Light Source is supported by the Director, Office of Science, Office of Basic Energy Sciences, of the U.S. Department of Energy under Contract No. DE-AC02-05CH11231. Xing-Zhong Shu is acknowledged for preparing the reactants that were used in the flow experiments. Selim Alayoglu is acknowledged for his assistance in the NEXAFS measurements. Parts of this work were conducted at the laboratories of Prof. G. A. Somorjai and Prof. F. D. Toste at UC Berkeley. 


\section{References}

[1] S. Alayoglu, J.M. Krier, W.D. Michalak, Z.W. Zhu, E. Gross, G.A. Somorjai, Acs Catalysis 2 (2012) 2250-2258.

[2] G.A. Somorjai, J.Y. Park, Physics Today 60 (2007) 48-53.

[3] G.A. Somorjai, J.Y. Park, Angewandte Chemie-International Edition 47 (2008) 9212-9228.

[4] A.T. Bell, Science 299 (2003) 1688-1691.

[5] L.J. Burcham, G. Deo, X.T. Gao, I.E. Wachs, Topics in Catalysis 11 (2000) 85-100.

[6] I.E. Wachs, C.A. Roberts, Chemical Society Reviews 39 (2010) 5002-5017.

[7] A.A. Lysova, I.V. Koptyug, Chemical Society Reviews 39 (2010) 4585-4601.

[8] F. Tao, S. Dag, L.W. Wang, Z. Liu, D.R. Butcher, H. Bluhm, M. Salmeron, G.A. Somorjai, Science 327 (2010) 850-853.

[9] F. Tao, M.E. Grass, Y.W. Zhang, D.R. Butcher, J.R. Renzas, Z. Liu, J.Y. Chung, B.S. Mun, M. Salmeron, G.A. Somorjai, Science 322 (2008) 932-934.

[10] E. Stavitski, B.M. Weckhuysen, Chemical Society Reviews 39 (2010) 4615-4625.

[11] J.M. Andanson, A. Baiker, Chemical Society Reviews 39 (2010) 4571-4584.

[12] L.R. Baker, G. Kennedy, M. Van Spronsen, A. Hervier, X.J. Cai, S.Y. Chen, L.W. Wang, G.A. Somorjai, Journal of the American Chemical Society 134 (2012) 14208-14216.

[13] G. Kennedy, L.R. Baker, G.A. Somorjai, Angewandte Chemie-International Edition 53 (2014) 3405-3408.

[14] F. Gao, Y.L. Wang, D.W. Goodman, Journal of Physical Chemistry C 114 (2010) 4036-4043.

[15] C. Rameshan, et al., Journal of Catalysis 276 (2010) 101-113.

[16] X.Z. Shu, M. Zhang, Y. He, H. Frei, F.D. Toste, Journal of the American Chemical Society 136 (2014) 5844-5847.

[17] N. Sivasankar, H. Frei, Journal of Physical Chemistry C 115 (2011) 7545-7553.

[18] M. Zhang, M. de Respinis, H. Frei, Nature Chemistry 6 (2014) 362-367.

[19] I.L.C. Buurmans, B.M. Weckhuysen, Nature Chemistry 4 (2012) 873-886.

[20] B.M. Weckhuysen, Chemical Communications (2002) 97-110.

[21] E. Gross, X.Z. Shu, S. Alayoglu, H.A. Bechtel, M.C. Martin, F.D. Toste, G.A. Somorjai, Journal of the American Chemical Society 136 (2014) 3624-3629.

[22] M.J. Nasse, M.J. Walsh, E.C. Mattson, R. Reininger, A. Kajdacsy-Balla, V. Macias, R. Bhargava, C.J. Hirschmugl, Nature Methods 8 (2011) 413-U58.

[23] M.H.F. Kox, K.F. Domke, J.P.R. Day, G. Rago, E. Stavitski, M. Bonn, B.M. Weckhuysen, Angewandte Chemie-International Edition 48 (2009) 8990-8994.

[24] E. Stavitski, M.H.F. Kox, I. Swart, F.M.F. de Groot, B.M. Weckhuysen, Angewandte ChemieInternational Edition 47 (2008) 3543-3547.

[25] E. Stavitski, E.A. Pidko, M.H.F. Kox, E.J.M. Hensen, R.A. van Santen, B.M. Weckhuysen, Chemistry-a European Journal 16 (2010) 9340-9348.

[26] W. Huang, J.N. Kuhn, C.K. Tsung, Y. Zhang, S.E. Habas, P. Yang, G.A. Somorjai, Nano Letters 8 (2008) 2027-2034.

[27] C.A. Witham, W.Y. Huang, C.K. Tsung, J.N. Kuhn, G.A. Somorjai, F.D. Toste, Nature Chemistry 2 (2010) 36-41.

[28] Y. Borodko, C.M. Thompson, W.Y. Huang, H.B. Yildiz, H. Frei, G.A. Somorjai, Journal of Physical Chemistry C 115 (2011) 4757-4767.

[29] Y.M. Li, et al., Journal of the American Chemical Society 133 (2011) 13527-13533.

[30] E. Gross, J.H. Liu, S. Alayoglu, M.A. Marcus, S.C. Fakra, F.D. Toste, G.A. Somorjai, Journal of the American Chemical Society 135 (2013) 3881-3886.

[31] E. Gross, J.H.C. Liu, F.D. Toste, G.A. Somorjai, Nature Chemistry 4 (2012) 947-952.

[32] E. Gross, F.D. Toste, G.A. Somorjai, Catalysis Letters 145 (2015) 126-138.

[33] B.D. Sherry, L. Maus, B.N. Laforteza, F.D. Toste, Journal of the American Chemical Society 128 (2006) 8132-8133.

[34] J.D. Grunwaldt, S. Hannemann, C.G. Schroer, A. Baiker, Journal of Physical Chemistry B 110 (2006) 8674-8680.

[35] D. Obermayer, A.M. Balu, A.A. Romero, W. Goessler, R. Luque, C.O. Kappe, Green Chemistry 15 (2013) 1530-1537. 
[36] T. Tsubogo, H. Oyamada, S. Kobayashi, Nature 520 (2015) 329-332.

[37] R.L. Hartman, J.P. McMullen, K.F. Jensen, Angewandte Chemie-International Edition 50 (2011) 7502-7519. 